\title{
Effect of Hot Drawing Process on Physical and Thermal Properties of Polypropylene Fiber Containing Selective Peroxide and Comparison with Conventional Polypropylene Fibers
}

\author{
Bahareh Kalantari, Mohammad R. M. Mojtahedi, Ahmad M. Shoushtari \\ Department of Textile Engineering, Amirkabir University of Technology \\ Aminoddin Haji \\ Textile Engineering Department, Birjand Branch, Islamic Azad University, Birjand, Iran
}

\begin{abstract}
In this research, the effect of the drawing process on the physical and thermal properties of commercially available polypropylene fiber containing selective peroxide was studied. Attempts have also been made to compare this drawn fiber sample with conventional polypropylene fibers produced from reactor and with controlled rheology grades. The results showed that the drawn PP/Peroxide fiber has higher birefringence, tenacity, and initial modulus compared with that of the drawn polypropylene fiber. Moreover, the fraction of load carrying chains in various drawn polypropylene fibers was evaluated on the basis of simplified models.
\end{abstract}

Keywords: Polypropylene fiber, peroxide, drawing process, orientation development, micromechanical model.

\section{Introduction}

The success of polypropylene for industrial applications lies in its versatility. Excellent chemical resistance, low density and highest melting point in the family of olefin fibers coupled with moderate cost make it an important fiber for industrial applications. Polypropylene resins produced in the most industrial polymerization process have a high molecular weight and broad molecular weight distribution. The level of elasticity of high molecular weight and broad molecular weight distribution polypropylene is very high and could cause some problems, for example, frozen elastic strain and draw resonance in high speed processing ${ }^{[1-3]}$. Generally, polypropylene resins with low melt viscosity as well as narrow molecular weight distribution are demanded in high speed spinning. In this case, the molecular weight distribution can be modified easily and economically in a simple post reactor process by incorporating peroxide to induce controllable degradation of polypropylene chains. The polypropylene produced in this way exhibited reduced viscosity and elasticity and also narrow molecular weight distribution compared to the parent commodity polymer ${ }^{[4-6]}$. This modification has been adopted in industry and it has been a popular research subject $^{[4-13]}$.

In common with the other synthetic fibers, the mechanical properties of polypropylene fibers are strongly influenced by their physical structures, which are controlled by both the choice of the starting material and the fiber formation conditions. The different conditions of the fiber formation during melt spinning and drawing processes cause different arrangements of the supermolecular structural elements, resulting in different fiber properties ${ }^{[14,15]}$. The structure and final properties of fibers also depend on their molecular structure, i.e., polymer molecular mass and molecular mass distribution $^{[16-18]}$.

As-spun polypropylene fibers possess mechanical properties that are much too inferior for practical application. The tenacity and initial modulus of the fibers are too low, and there is also a high, irreversible elongation. However, as with other synthetic fibers, drawing under carefully controlled conditions can markedly improve mechanical performance of polypropylene fibers. The properties of drawn polypropylene depend on molecular weight, molecular weight distribution, initial morphology, drawing temperature and strain rate. Various views of structural and property changes resulting from drawing process have been extensively investigated ${ }^{[19-21]}$.

In our previous investigation, the effect of addition of selective peroxide to a broad MWD polypropylene granule (known as V30S) during melt spinning was investigated ${ }^{[22]}$. Also the mechanical and thermal properties of as-spun V30S/Peroxide fiber were compared with conventional polypropylene fibers with different structures. The purpose of this work is to investigate structural property relationships for the drawn V30S/Peroxide and three conventional polypropylene fibers with different structures.

\section{Experimental}

\section{Materials}

Multifilament yarns were spun from three commercial fibre grade isotactic polypropylene granules, known as 512P (Sabic Co., Saudi Arabia), a fibre grade controlled rheology (CR) polymer, V30S and Z30S (Arak Petrochemical Co., Iran). General characteristics of these granules have been shown in Table 1.

512P granule is a narrow molecular weight distribution polymer whereas V30S and Z30S granules have broad molecular weight distributions. These materials are normally considered to stable against weathering oxidation, since those are contained usual synergistic combination of antioxidants that are found in commercial granules. The peroxide used for degradation of PP was 2,5-dimethyl-di(t-butylperoxy)hexane, (DHBP, Trigonox 101 from Akzo Chemie, Amersfoort, The Netherlands).

\section{Preparation of melt-spun filaments}

Melt spinning was performed under nitrogen gas on a FourneAutomatic melt spinning unit (pilot plant). The details of melt spinning process described in the previous work ${ }^{[22]}$. Briefly, the polymer melts were extruded at a rate of $100 \mathrm{~g} / \mathrm{min}$ through a spinneret with 36 circular orifices, each of $0.25 \mathrm{~mm}$ diameter. The 
as-spun filaments were collected at a take-up speed of $2000 \mathrm{~m} / \mathrm{min}$. The final linear density of multifilament yarns was 140 dtex. For spinning fiber from V30S/Peroxide sample, we first determined the optimum concentration of peroxide which has been determined in our previous work ${ }^{[22]}$. After examining the spinnability of V30S/ Peroxide sample with different concentration of peroxide, we choose amount of 0.3 wt. (\%) peroxide for mixing with V30S granule. We choose a relatively high extruder barrel temperature to be sure that the degradation reaction is finished upon reaching the die exit due to the very short half-life time of peroxide at this temperature.

\section{Drawing process}

The drawing was carried out on an industrial Zinser drawtwisting machine (Germany), type 520-2. The constant draw ratio of $\mathrm{DR}=2$ was selected for drawing of all samples. The drawing conditions are given in Table 2. Number of wraps round each godet roller defines the contact time of multifilament yarn with corresponding temperature. These conditions were deduced from preliminary experimental.

\section{Characterization techniques}

Yarn linear density (expressed in dtex) was determined in accordance with ASTM D 1577-96. Mean values are the average of five measurements.

The fringe shift inside the fibers was measured by a crosspolarized optical microscope (Carl Zeiss, Jena, Germany) and birefringence was calculated using the following equation ${ }^{[23]}$ :

$$
\Delta n=\frac{d z \cdot \lambda}{z \cdot d}
$$

where $\mathrm{dz}$ is a fringe shift inside the fiber, $\mathrm{z}$ is an interfringe spacing, $\lambda$ is the wavelength of the monochromatic light used (in our case, $\lambda=550 \mathrm{~nm}$ ), and $\mathrm{d}$ is the fiber thickness. Hermans orientation factor $(\mathrm{F})$ is related to the refractive index difference by the relation ${ }^{[24]}$ :

$$
F=\frac{\Delta n}{\Delta n^{*}}
$$

where $\Delta \mathrm{n} *$ is the intrinsic maximum birefringence which corresponds to the case where all the molecule are perfectly aligned. The value of $\Delta \mathrm{n} *$ for polypropylene fiber was taken to be $0.045^{[25]}$. The optical orientation angle $\theta$ can be calculated by Hermans orientation factor from the following equation:

$$
\theta=\sin ^{-1}\left(\frac{2}{3}(1-F)\right)^{\frac{1}{2}}
$$

Densities of fibers were determined by a floatation method. A binary medium prepared from various ratios of distilled water and

Table 1. Characterization of as-received granules.

\begin{tabular}{lccc}
\hline & 512P & V30S & Z30S \\
\hline Molecular weight $(\mathrm{g} / \mathrm{mol})$ & 186036 & 225552 & 191337 \\
Molecular weight distribution & 2.59 & 4.14 & 3.76 \\
Melt flow index (g/10 min) & 25 & 16 & 25 \\
\hline
\end{tabular}

ethyl alcohol was used at $23{ }^{\circ} \mathrm{C}$. The crystalline fraction (X) of the yarn samples was then estimated using the following expression:

$$
X=\frac{\left(\rho-\rho_{a}\right)}{\left(\rho_{c}-\rho_{a}\right)} \times \frac{\rho_{c}}{\rho}
$$

where $\rho$ is sample density and $\rho_{c}$ and $\rho_{\text {a }}$ are densities of crystalline and amorphous polypropylene and were taken to be $0.9363 \mathrm{~g} . \mathrm{cm}^{-3}$ and $0.8576 \mathrm{~g} . \mathrm{cm}^{-3}$, respectively ${ }^{[26]}$.

Stress-strain curves were obtained using an Instron tensile tester model $5566 \mathrm{H} 1730$. A gauge length of $200 \mathrm{~mm}$ and crosshead speed of $500 \mathrm{~mm} / \mathrm{min}$ were employed. From stress-strain plots, the modulus, tenacity and percentage extension at break were evaluated. The reported values of all the mechanical properties have been averaged over at least twenty independent measurements.

Differential scanning calorimetry (DSC) measurements were carried out on DSC 2010 machine (TA Instruments, New Castle, DE, USA) to examine the melting behavior of multifilament yarns. Samples of $5 \mathrm{mg}$, which were cut from the fibers, were heated from room temperature to $210{ }^{\circ} \mathrm{C}$ at a scanning rate of $10{ }^{\circ} \mathrm{C} / \mathrm{min}$ under nitrogen atmosphere. The equipment was calibrated with indium. From the heat of fusion, an apparent crystallinity (X) was determined by following equation:

$$
X(\%)=\left(\Delta H / \Delta H^{*}\right) \times 100
$$

where $\Delta H$ is the measured melting enthalpy and $\Delta \mathrm{H}^{*}$ is the enthalpy

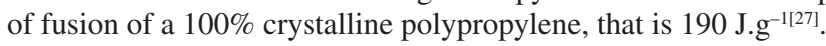

The yarn shrinkages were measured after heating a freely hanged length of yarns in an oven at $130{ }^{\circ} \mathrm{C}$ for 10 minutes according to DIN 53840. The initial and final lengths were measured at room temperature and the shrinkage calculated as percent change in length relative to the initial length. The average of five measurements was reported as the shrinkage.

\section{Results and Discussion}

\section{Birefringence}

Several characteristics of multifilament yarns are shown in Table 3. The birefringence values and orientation factors of the drawn fibers are shown in Figure 1. As can be seen in Figure 1 and Table 3, the drawn 512P fiber has the highest birefringence and orientation factor followed by the drawn V30S/Peroxide, V30S and Z30S fibers. The highest orientation angle appeared in drawn Z30S fiber. As expected and according to Equation 3, orientation angle data in Table 3 are basically the inverse of the orientation factor data. The orientation factor equals unity and the orientation angle equals zero when the fiber material become fully oriented and all polymer chains were aligned parallel to the fiber axis.

The birefringence of the drawn V30S/Peroxide fibers is higher than that of the drawn V30S fiber. It seems that the peroxide facilitates the orientation development in V30S/Peroxide fiber by lowering the entanglements in V30S polymer chains. Therefore,

\begin{tabular}{|c|c|c|c|c|c|c|c|c|c|}
\hline $\begin{array}{l}\text { Temperature } \\
\text { of first draw } \\
\text { roller } \\
\left({ }^{\circ} \mathrm{C}\right) \\
\end{array}$ & $\begin{array}{c}\text { Temperature } \\
\text { of first godet } \\
\text { roller } \\
\left({ }^{\circ} \mathrm{C}\right) \\
\end{array}$ & $\begin{array}{c}\text { Temperature } \\
\text { of hot plate } \\
\left({ }^{\circ} \mathbf{C}\right)\end{array}$ & $\begin{array}{l}\text { Temperature } \\
\text { of second } \\
\text { godet roller } \\
\left({ }^{\circ} \mathrm{C}\right)\end{array}$ & $\begin{array}{l}\text { First } \\
\text { stage } \\
\text { draw } \\
\text { ratio } \\
\end{array}$ & $\begin{array}{l}\text { Number of } \\
\text { wraps round } \\
\text { first godet } \\
\text { roller }\end{array}$ & $\begin{array}{c}\text { Number of } \\
\text { wraps round } \\
\text { second godet } \\
\text { roller }\end{array}$ & $\begin{array}{c}\text { Drawing } \\
\text { speed } \\
(\mathrm{m} / \mathrm{min})\end{array}$ & $\begin{array}{l}\text { Intermingling } \\
\text { jet pressure } \\
\text { (bar) }\end{array}$ & $\begin{array}{c}\text { Spindle } \\
\text { speed } \\
\text { (rpm) }\end{array}$ \\
\hline $\begin{array}{c}\text { Room } \\
\text { temperature }\end{array}$ & 120 & 140 & 140 & 1.008 & 8 & 6 & 400 & 2 & 4000 \\
\hline
\end{tabular}
during hot drawing process, the V30S/Peroxide fiber has higher molecular mobility and this decreases the resistance of the polymer network to deformation. Consequently, the efficiency of chain

Table 2. The operating conditions of drawing process. 
Table 3. Characteristics of the drawn and as-spun multifilament yarns spun from different polypropylene granules.

\begin{tabular}{lcccccccccc}
\hline Fiber sample & \multicolumn{2}{c}{$\begin{array}{c}\text { Birefringence } \\
\left(\times \mathbf{1 0}^{\mathbf{3}}\right)\end{array}$} & \multicolumn{2}{c}{ Orientation factor } & \multicolumn{2}{c}{$\begin{array}{c}\text { Orientation angle } \\
\left(\theta^{\mathbf{0}}\right)\end{array}$} & \multicolumn{2}{c}{$\begin{array}{c}\text { Density } \\
\left(\mathbf{g r} / \mathbf{c m}^{\mathbf{3}}\right)\end{array}$} & $\begin{array}{c}\text { Crystallinity } \\
(\mathbf{b y ~ d e n s i t y , ~ \% ) ~}\end{array}$ \\
\cline { 2 - 11 } & As-spun & Drawn & As-spun & Drawn & As-spun & Drawn & As-spun & Drawn & As-spun & Drawn \\
\hline 512P & 22.71 & 32.22 & 0.50 & 0.71 & 35.26 & 26.08 & 0.8987 & 0.9055 & 54.40 & 62.91 \\
V30S/Pexide & 21.67 & 30.80 & 0.48 & 0.68 & 36.07 & 27.5 & 0.9009 & 0.9064 & 57.18 & 64.05 \\
V30S & 20.22 & 28.30 & 0.45 & 0.63 & 37.26 & 29.82 & 0.9008 & 0.9071 & 57.05 & 64.92 \\
Z30S & 19.17 & 27.90 & 0.43 & 0.62 & 38.05 & 30.22 & 0.9025 & 0.9084 & 59.18 & 66.53 \\
\hline
\end{tabular}

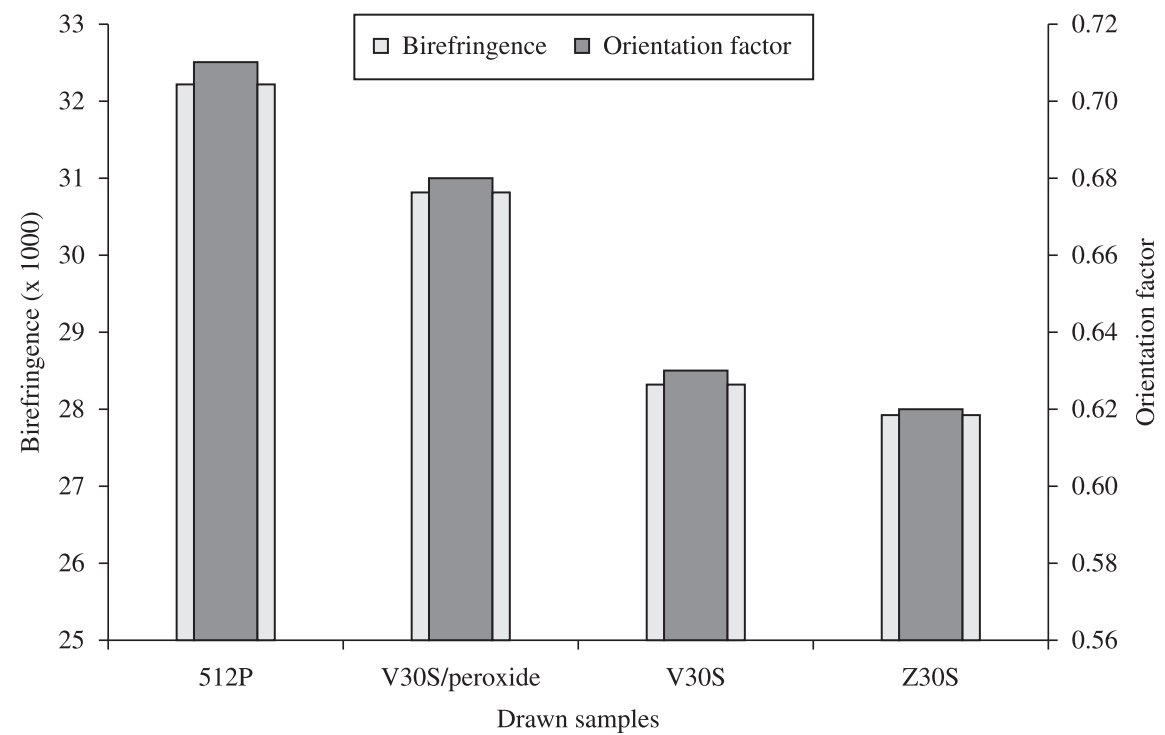

Figure 1. The birefringence and orientation factors of the drawn yarns.

orientation during drawing of V30S/Peroxide fiber increases and gives rise to higher birefringence value.

\section{Density}

The densities of the drawn fibers and calculated crystalline fraction from density measurements are shown in Figure 2.

It can be seen from Figure 2, the drawn 512P fiber has the lowest density values among all studied polymers whereas the drawn Z30S fiber polymer exhibited the highest mentioned values. It should be noted that the density and calculated crystallinity of drawn V30S fiber are slightly higher than that of the drawn V30S/Peroxide fiber.

Previous study ${ }^{[18]}$ showed that the fibers spun form polymer with higher molecular weight and broader molecular weight distribution show higher density due to higher amount of stress applied in the spin line. The greater density of the drawn Z30S fiber compared to that of the drawn V30S/Peroxide fiber is consistent with this theory, as shown in Figure 2.

On this point, it should be underlined that in the course of drawing of semicrystalline polymers, such as polypropylene, the crystallinity can increase or decrease or even remains unchanged depending on several factors: the drawing conditions (draw ratio, draw rate, and temperature), the starting structure and the chemical nature and composition of the polymeric system ${ }^{[28]}$. In our results, drawing process increases the crystallinity of fiber samples due to increase in orientation.

\section{Thermal analysis}

The results of DSC analysis of the as-spun and the drawn fibers are summarized in Table 4.
As can be seen in Table 4, in contrast to as-spun fibers, significant differences were observed in first melting point and melting enthalpy of the drawn fibers. But, the differences in the temperature of second melting point between the drawn fibers were not considerable. The drawn 512P fiber presented the lowest first melting point and melting enthalpy whereas the drawn Z30S fiber showed the highest ones.

As can be seen in Table 4, the DSC data of undrawn fibers spun from V30S/Peroxide, V30S and Z30S show a single melting peak. It seems that some crystals in as-spun fibers destructed during hot drawing and therefore, the crystals with different sizes and perfections formed in drawn fibers. Small and less regular crystals melt at lower temperature while the melting of the more perfect and larger crystals occurs at higher temperature. This may explain that why the DSC data of the drawn V30S/Peroxide, V30S, and Z30S fibers show a double melting peak. It is clear from Table 4, the first melting point of as-spun fibers shifted to lower temperatures comparing to the drawn samples.

DSC thermograms of the drawn fibers are illustrated in Figure 3. All drawn fibers show a double endotherm peak. The presence of double endotherm peaks in the drawn fibers shows that the crystals with different sizes, perfections and stabilities are present in these samples. The melting and recrystallization of small and imperfect crystals during DSC heating cause a double melting peak appeared in the drawn fibers.

As shown in Table 3, the molecular orientation increases strongly by drawing and the molecular rearrangements occurred during hot drawing process seem to be enhancing the chance of neighboring chains falling into crystalline regions. This idea can be explained the higher crystallinity in drawn fibers as compared to as-spun fibers (see Table 4). 


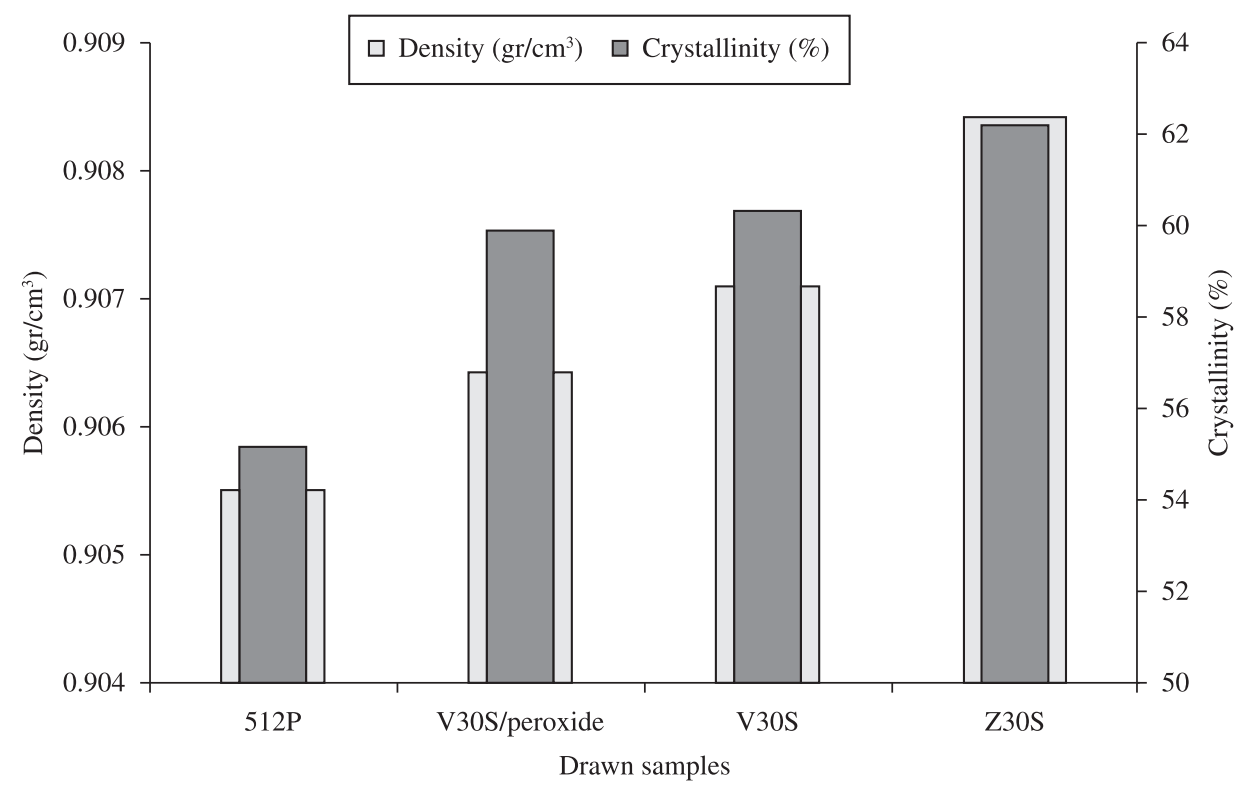

Figure 2. The density and crystallinity calculated from density of the drawn fibers.

Table 4. Thermal properties of the drawn multifilament yarns.

\begin{tabular}{lcccccccc}
\hline Fiber sample & \multicolumn{2}{c}{ First melting point $\left({ }^{\circ} \mathbf{C}\right)$} & \multicolumn{2}{c}{ Second melting point $\left({ }^{\circ} \mathbf{C}\right)$} & \multicolumn{2}{c}{ Melting enthalpy $(\mathbf{J} / \mathbf{g})$} & \multicolumn{2}{c}{ Crystallinity $(\%)$} \\
\cline { 2 - 10 } & As-spun & Drawn & As-spun & Drawn & As-spun & Drawn & As-spun & Drawn \\
\hline 512P & 159.57 & 154.06 & 164.40 & 167.13 & 98.94 & 104.80 & 52.07 & 55.15 \\
V30S/Peroxide & 162.66 & 159.77 & -------- & 166.17 & 102.90 & 113.80 & 54.15 & 59.89 \\
V30S & 163.69 & 160.02 & -------- & 166.57 & 101.50 & 114.50 & 53.42 & 60.26 \\
Z30S & 163.83 & 160.54 & -------- & 168.64 & 106.30 & 118.10 & 55.94 & 62.15 \\
\hline
\end{tabular}

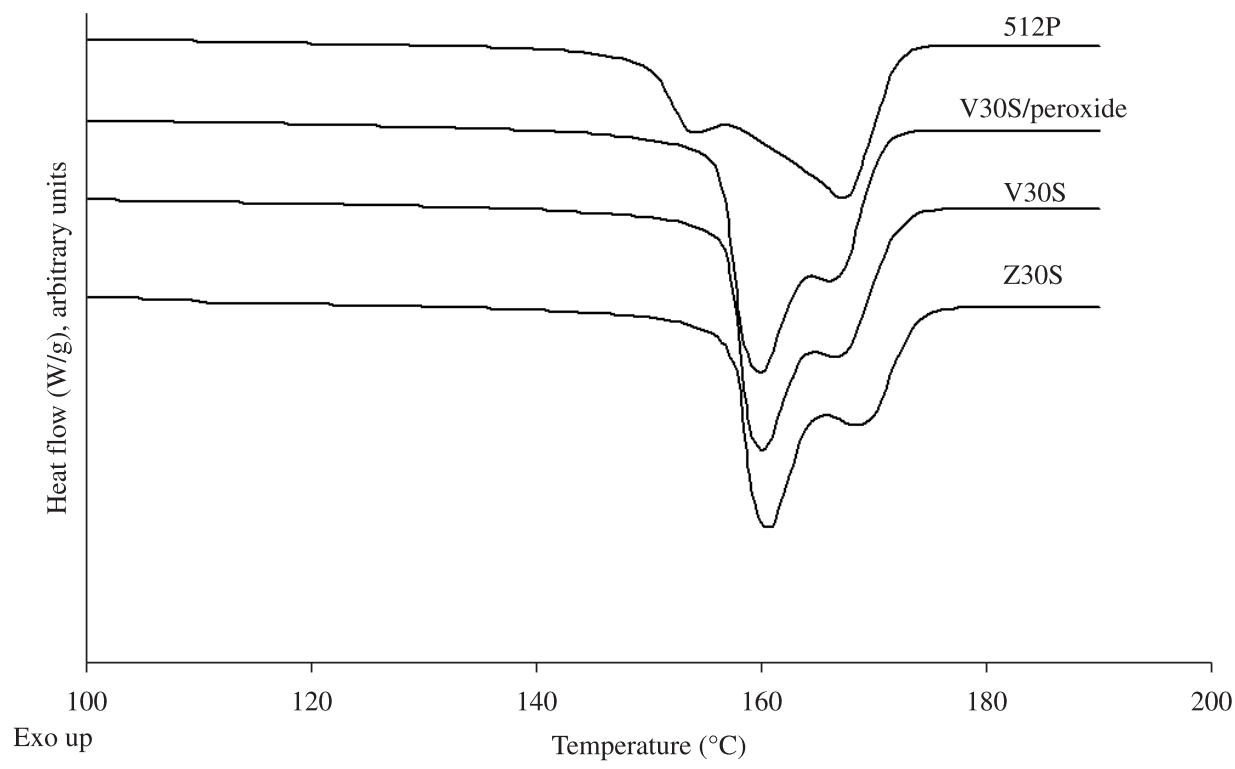

Figure 3. Heating cycles of DSC thermograms for the drawn fibers.

\section{Mechanical properties}

The mechanical properties and the shrinkage values of the drawn samples are presented in Table 5. Since the mechanical properties of the drawn fibers depend also on as-spun fiber characteristics, the mechanical properties of as-spun fibers are shown in Table 5 as well.

The fiber drawing was found to be effective in the improvement of the mechanical properties. The drawing leads to an increase in tenacity and initial modulus but a drop in elongation at break. We can see in Table 5 a great decrease in fiber extensibility, much more than the increase of the tenacity and initial modulus. The elongations at break in Table 5 are basically the inverse of the tenacity data. These results reflect the observed differences in orientation of the filaments as measured by the birefringence values (see Table 3 ).

The tenacity or specific stress of fibers, determined as a tensile force at break over the undeformed yarn linear density and the true 
tenacity, defined the ratio of the tensile force at break to the yarn linear density at the time of breakage, are seen in Figure 4.

The drawn 512P fiber has the highest tenacity followed by the drawn V30S/Peroxide, V30S, and Z30S fibers. The tenacities of the drawn V30S and Z30S fibers did not show significant difference. The tenacity values show that the addition of peroxide to V30S granule can increase this value around $21 \%$ for the drawn V30S/ Peroxide fiber comparing to that of the drawn V30S fiber. As can be seen in Table 5, this improvement in tenacity of as-spun fibers spun from V30S/Peroxide as compared to as-spun fibers spun from pure V30S was $10 \%$ and this shows that the role of peroxide amplified in the post-spinning process. It seems that the peroxide decreases the entanglement density and also chance of stress concentration in V30S fiber chains, thereby the opening of entanglements during drawing improves and this gives rise to higher tenacity in the drawn V30S/Peroxide fiber in comparison to that of the drawn V30S fiber.

Due to absence of significant difference in crystallinity of the drawn fibers (Table 4), we discourage the use of this parameter to correlate the observed tensile values with structure and morphology. Therefore, it is tempting to consider orientation as a main factor for improving tenacity of the drawn fibers.
It is observed from Figure 5, the drawn 512P fiber has the highest initial modulus values followed by the drawn V30S/Peroxide, V30S, and Z30S fibers.

It is interesting to note that the observed trend in initial modulus values of the drawn fibers is opposite of current trend in their as-spun fibers. Generally, initial modulus is highly related to the crystallinity, crystal size, and orientation ${ }^{[29]}$. In spite of negligible difference between the crystallinity values of the drawn fibers, the improvement in initial modulus obtained for drawn fibers, indicating that the orientation is the most responsible for the improvement in the initial modulus (see Table 3). These results confirmed this fact that the polypropylene fibers with narrower molecular weight distribution have higher potential to obtain higher modulus and tenacity in the drawn fibers.

\section{Shrinkage}

The results of hot air shrinkage experiment are given in Table 5 . As can be seen in Table 5, the shrinkage values of the drawn fibers have no significant difference. It seems that due to performing draw process in temperature of $140{ }^{\circ} \mathrm{C}$, the shrinkage experiment at

Table 5. Tensile properties and shrinkage values of undrawn and drawn fibers.

\begin{tabular}{|c|c|c|c|c|c|c|c|c|c|c|}
\hline \multirow[t]{2}{*}{ Fiber sample } & \multicolumn{2}{|c|}{$\begin{array}{l}\text { Nominal tenacity } \\
(\mathrm{cN} / \mathrm{tex})\end{array}$} & \multicolumn{2}{|c|}{$\begin{array}{l}\text { True tenacity } \\
(\mathbf{c N} / \text { tex })\end{array}$} & \multicolumn{2}{|c|}{$\begin{array}{c}\text { Elongation at break } \\
(\%)\end{array}$} & \multicolumn{2}{|c|}{$\begin{array}{c}\text { Initial modulus } \\
(\mathrm{cN} / \mathrm{tex})\end{array}$} & \multicolumn{2}{|c|}{$\begin{array}{c}\text { Shrinkage } \\
(\%)\end{array}$} \\
\hline & As-spun & Drawn & As-spun & Drawn & As-spun & Drawn & As-spun & Drawn & As-spun & Drawn \\
\hline \multirow{2}{*}{$512 \mathrm{P}$} & 19.99 & 38.80 & \multirow{2}{*}{59.43} & \multirow{2}{*}{49.77} & 197.30 & 28.28 & 124.40 & 285.40 & 1.50 & 4.38 \\
\hline & $(0.8)$ & $(1.41)$ & & & $(9.04)$ & $(4.02)$ & $(4.48)$ & $(8.55)$ & $(0.10)$ & $(0.10)$ \\
\hline \multirow{2}{*}{ V30S/Peroxide } & 15.00 & 32.41 & \multirow{2}{*}{57.01} & \multirow{2}{*}{42.21} & 280.10 & 30.26 & 139.10 & 242.90 & 1.81 & 4.24 \\
\hline & $(0.7)$ & $(1.07)$ & & & $(26.21)$ & $(3.48)$ & $(5.81)$ & $(9.14)$ & $(0.21)$ & $(0.16)$ \\
\hline \multirow{2}{*}{ V30S } & 13.68 & 26.87 & \multirow{2}{*}{56.75} & \multirow{2}{*}{36.39} & 314.90 & 35.44 & 148.10 & 209.20 & 2.09 & 4.17 \\
\hline & $(0.4)$ & $(1.57)$ & & & $(12.16)$ & $(4.48)$ & $(5.39)$ & $(9.84)$ & $(0.10)$ & $(0.19)$ \\
\hline \multirow{2}{*}{$\mathrm{Z} 30 \mathrm{~S}$} & 13.54 & 25.37 & \multirow{2}{*}{59.27} & \multirow{2}{*}{34.74} & 337.80 & 36.94 & 151.30 & 201.00 & 1.85 & 4.26 \\
\hline & $(0.45)$ & (1.04) & & & $(10.08)$ & (3.94) & (5.74) & (11.26) & $(0.17)$ & $(0.22)$ \\
\hline
\end{tabular}

The numbers in parentheses are standard deviation.

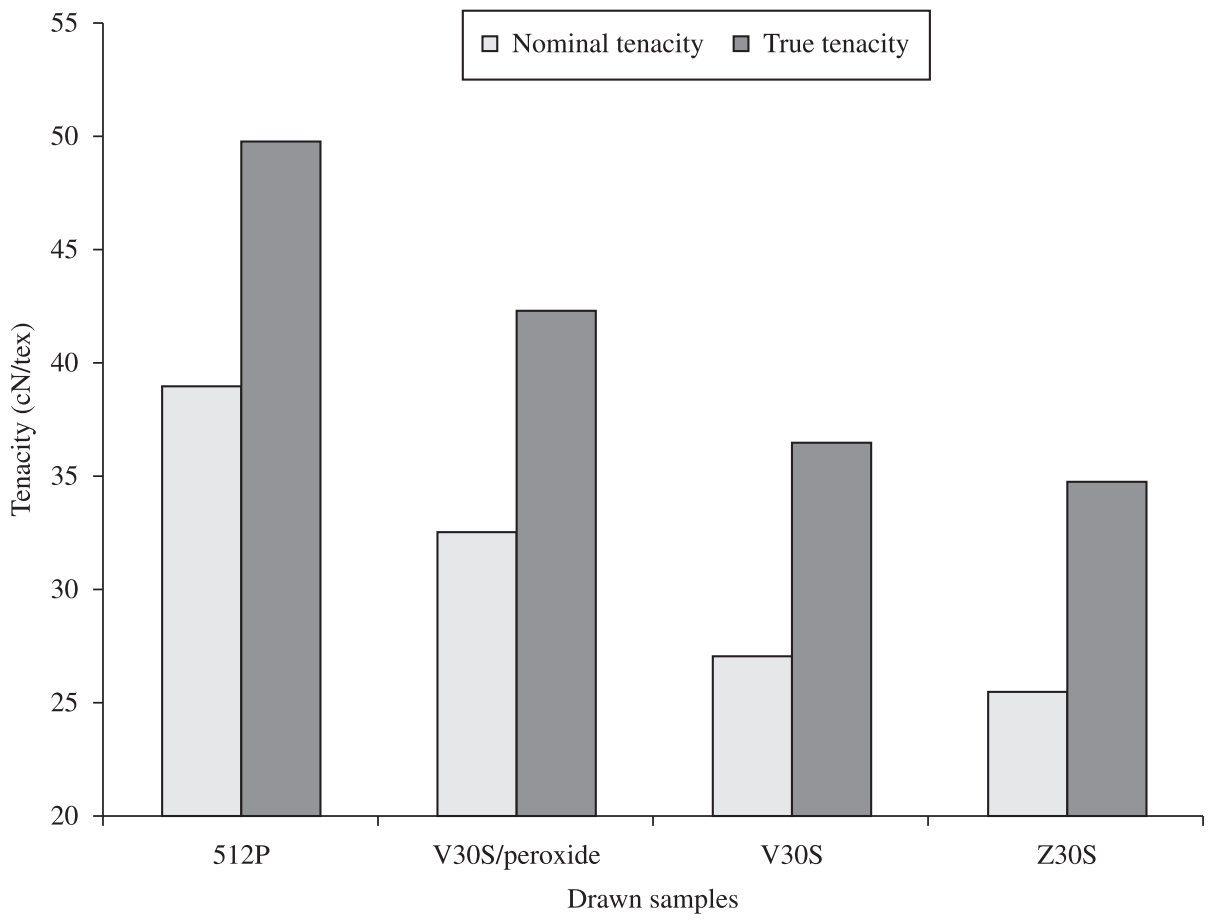

Figure 4. The nominal and true tenacities of the drawn fibers. 
$130{ }^{\circ} \mathrm{C}$ could not show the structure differences in the drawn fibers and they all show almost the same shrinkage value. Moreover, the shrinkage values of the drawn fibers are higher than those of the as-spun fibers due to applied tension and unrelaxed during drawing.

It is typically observed that shrinkage values are very low, indicating very high dimensional stability of the drawn samples (see Table 5). The excellent dimensional stability is associated with the filament being drawn at fairly high temperatures $\left(140^{\circ} \mathrm{C}\right)$. High levels of crystallinity possibly can result in restriction of molecular movement in the amorphous zones. This could be a major reason for the low shrinkage values.

\section{Micromechanical modeling}

Peterlin $^{[30]}$ described that an increase in the fraction of tauttie molecules (TTM) means a decrease in the number of folded chains, which results in the increase of modulus. At very small stresses, the response of axially strained fibers is described by the initial modulus. Following Takayanagi ${ }^{[31]}$, the fibrous structure can be regarded as a multi-phase system, where the various phases correspond to extended-chain crystals (ECC), TTM and amorphous material. Polymer chains in extended conformation, i.e. ECC and TTM, are characterized by the crystal modulus of the polymer $\mathrm{E}_{\mathrm{c}}$, whereas the amorphous material is characterized by $\mathrm{E}_{\mathrm{a}}$. In the case of polypropylene, $\mathrm{E}_{\mathrm{c}}$ is estimated at $40 \mathrm{GPa}$, whereas $\mathrm{E}_{\mathrm{a}}$ is in the order of magnitude of $0.01 \mathrm{GPa}^{[32,33]}$.

The overall initial modulus of the composite structure depends on the relative amounts of ECC, TTM and the amorphous material, and on the way in which they are mechanically coupled. Basically, two different types of mechanical coupling can be discerned. The arrangements are shown in Figure 6, including "uniform-stress" (Figure 6a) and "uniform-strain" (Figure 6b) ${ }^{[34]}$.

In uniform-stress model, where the TTM are considered as disordered materials and do not contribute to the heat of fusion of the fiber, the TTM fraction $\beta$ can be calculated from the following equation:

$$
\beta=\frac{\left(E / E_{c}\right)\left(1-X_{c}\right)}{1-X_{c}\left(E / E_{c}\right)}
$$

where $\mathrm{E}$ and $\mathrm{E}_{\mathrm{c}}$ are observed initial modulus and crystal modulus of polypropylene, respectively, and $\mathrm{X}_{\mathrm{c}}$ is the obtained crystallinity from DSC method.

If, however, the TTM are considered as crystalline bridges and do contribute to the heat of fusion of the fiber, the TTM can be calculated according to:

$$
\beta=\frac{\left(E / E_{c}\right)\left(1-X_{c}\right)}{1-\left(E / E_{c}\right)}
$$

Comparing Equations 6 and 7 shows how, for a series arrangement, the calculated value for $\beta$ slightly depends on the assumptions concerning the crystallinity of the TTM.

In the case of a parallel arrangement shown in Figure 6b, the TTM fraction $\beta$ can be calculated using the following equation:

$$
\beta=\frac{E}{E_{c}}\left[1-\frac{\left(E_{c} / E\right)-1}{\left(1-X_{c}\right)\left(\left(E_{c} / E_{a}\right)-1\right)}\right]
$$

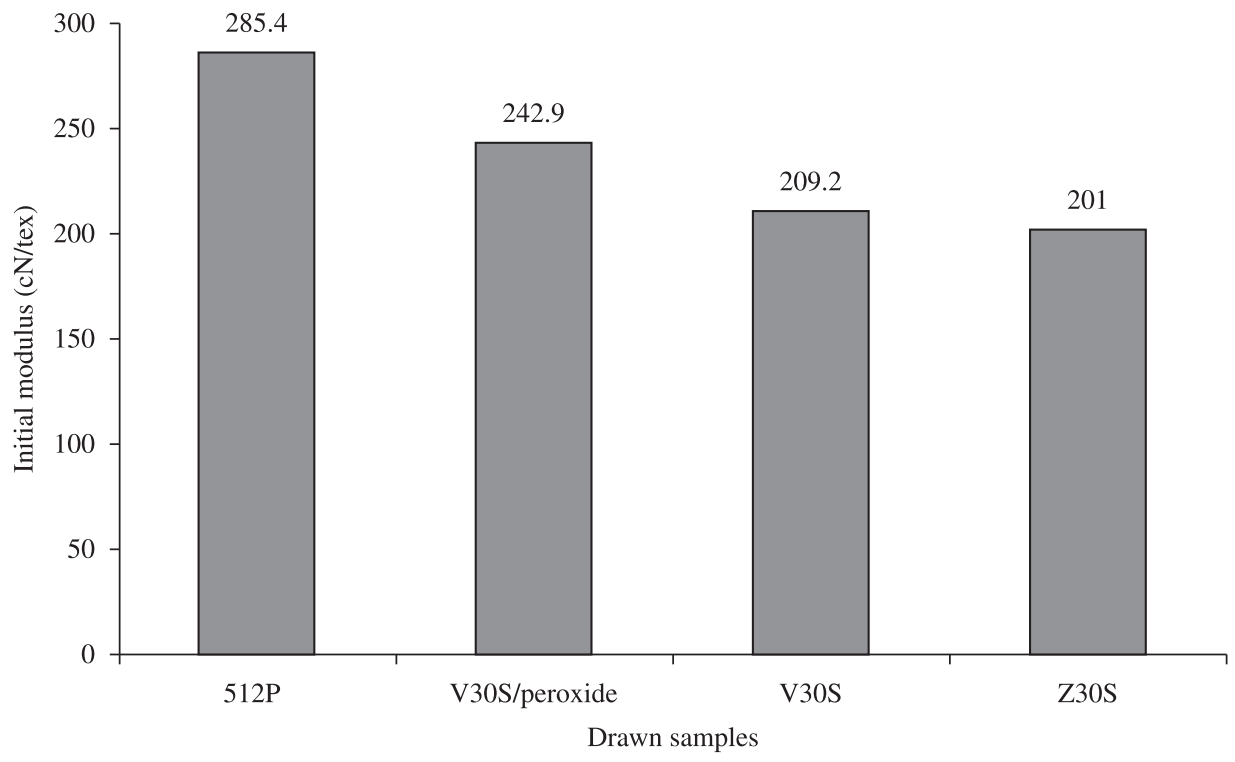

Figure 5. The initial modulus values of the drawn fibers.

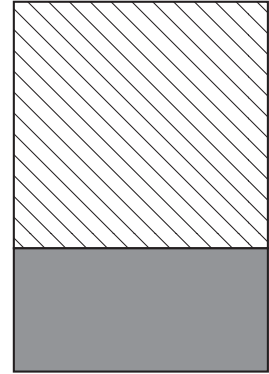

(a)

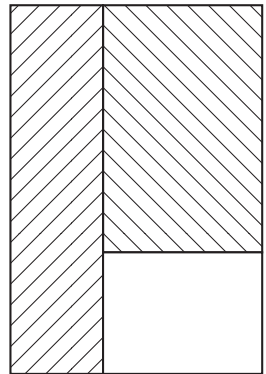

(b)

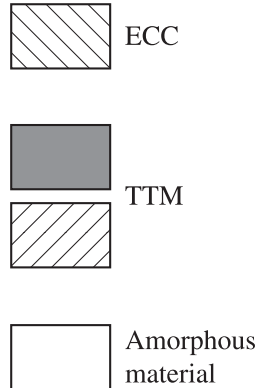
material

Figure 6. Schematic representation of the fiber structure with ECC, TTM and amorphous material (a) uniform-stress model and (b) uniform-strain model ${ }^{[34]}$. 


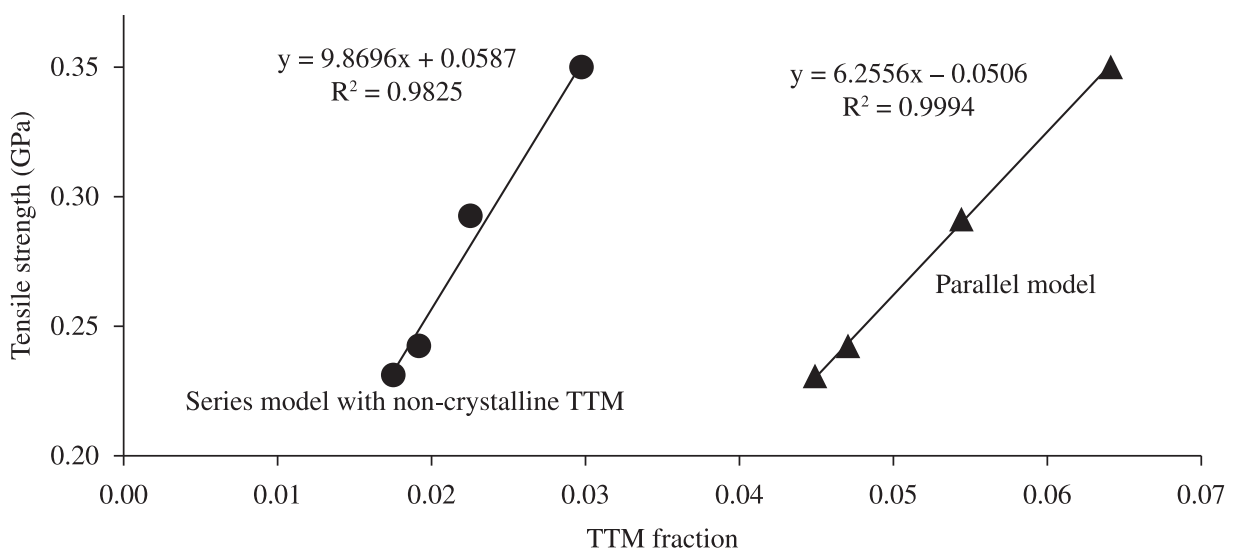

Figure 7. The strength of the drawn fibers as function of the TTM fraction using different models.

Table 6. Results of TTM fraction $\beta$ calculated for the drawn fibers from different models.

\begin{tabular}{lccccc}
\hline Fiber sample & $\begin{array}{c}\text { Initial } \\
\text { modulus } \\
(\mathbf{G P a})\end{array}$ & $\beta_{1}$ & $\beta_{2}$ & $\beta_{3}$ & $\begin{array}{c}\text { Tensile } \\
\text { strength } \\
(\mathbf{G P a})\end{array}$ \\
\hline 512P & 2.56 & 0.0297 & 0.0306 & 0.064 & 0.349 \\
V30S/Peroxide & 2.18 & 0.0225 & 0.0231 & 0.054 & 0.291 \\
V30S & 1.88 & 0.0192 & 0.0195 & 0.047 & 0.241 \\
Z30S & 1.80 & 0.0175 & 0.0178 & 0.045 & 0.231 \\
\hline
\end{tabular}

$\beta_{1}$ ) calculated according to Equation 6 , series coupling with non-crystalline TTM. $\beta_{2}$ ) calculated according to Equation 7, series coupling with crystalline TTM. $\beta_{3}$ ) calculated according to Equation 8, parallel coupling.

Table 7. Results of strength vs. TTM fraction plots obtained by linear regression, using different models for the calculation the TTM fraction $\beta$.

\begin{tabular}{lccc}
\hline \multicolumn{1}{c}{ Model } & $\begin{array}{c}\text { Strength } \\
\text { at } \beta=\mathbf{0} \\
(\mathbf{G P a})\end{array}$ & $\begin{array}{c}\text { Strength } \\
\text { at } \beta=\mathbf{1} \\
(\mathbf{G P a})\end{array}$ & $\begin{array}{c}\text { Regression } \\
\text { coefficient } \\
\left(\mathbf{R}^{2}\right)\end{array}$ \\
\hline $\begin{array}{l}\text { Series, TTM non-crystalline } \\
\text { (Equation 6) }\end{array}$ & $\cong 0$ & 9.92 & 0.99 \\
Parallel (Equation 8) & $\cong 0$ & 6.20 & 0.98 \\
\hline
\end{tabular}

Thus, depending on the type of mechanical coupling that is assumed to be present in realistic fibers, we are able to calculate $\beta$ from experimental modulus and crystallinity data.

The calculated TTM fractions are presented in Table 6. The TTM fraction $\beta_{1}, \beta_{2}$, and $\beta_{3}$ were calculated according to Equations 6, 7, and 8 , respectively.

Now that we have established the TTM fraction according to different modeling schemes, a value for the theoretical strength may be derived from the relation $\sigma=\beta \sigma_{\text {th }}$, i.e. by plotting the strength vs. the TTM fraction and extrapolation to $\beta=1$. In Figure 7 , such a plot is presented for the parallel model and series model with noncrystalline TTM.

In Table 7, the linear regression results of these plots are given. Clearly, both models give good fit according to the coefficient of regression $\mathrm{R}^{2}$. The series model predicts theoretical strength of 9.92 $\mathrm{GPa}$ while the parallel model predicts the lower strength of $6.20 \mathrm{GPa}$. Both predicted tensile strength values in these models are higher than that of the reported value previously for polypropylene which is $4 \mathrm{GPa}^{[35]}$. From another perspective of interpretation, the increase in tensile modulus and tenacity with increasing draw ratio was previously attributed to the increased fraction of the tie molecules connecting the adjacent crystallites in the microfibril and formation the highly ordered non-crystalline interfibrillar phase ${ }^{[36,37]}$. It is expected that the drawn 512P and V30S/Peroxide fibers with higher tenacity and initial modulus, have higher taut tie molecules and it seems that the parallel model shows this fact better (see Table 6). Therefore, the parallel arrangement with TTM is probably better model of the structure of our drawn polypropylene fibers.

\section{Conclusions}

By considering the effect of hot drawing on the structure and properties of polypropylene fibers having different molecular weight and molecular weight distribution, we are able to draw the following conclusions. Superior properties in terms of initial modulus and tenacity have been observed in the drawn V30S/ Peroxide with just $0.3 \mathrm{wt}$. (\%) of peroxide. Improvement in tensile properties in the drawn V30S/Peroxide fibers is observed even with the same crystallinity as compared to that of the drawn V30S fiber and this can be related to increase orientation. The results show that the peroxide facilitates the chain sliding and therefore, orientation development in as-spun V30S/Peroxide fiber during drawing. It was found that the parallel arrangement with taut tie molecules (TTM) can explain the mechanical properties obtained for the drawn polypropylene fibers.

\section{References}

1. Ahmed, M. - "Polypropylene Fiber Science and Technology", Elsevier, Amesterdam (1982).

2. Sheng, B.-R.; Li, B.; Xie, B.-H.; Yang, W.; Feng, J.-M. \& Yang, M.B. - Polym. Deg. Stab., 93, p.225 (2008). http://dx.doi.org/10.1016/j. polymdegradstab.2007.09.011

3. Ryu, S. H.; Gogos, C. G. \& Xanthos, M. - Polymer, 32, p.2449 (1991). http://dx.doi.org/10.1016/0032-3861(91)90088-Z

4. Haung, J.-C. \& Sirani, V. - Int. J. Polym. Mat., 46, p.151 (2000).

5. Tzoganakis, C.; Vlachopoulos, J. \& Hamielec, A. E. - Polym. Eng. Sci., 28, p.170 (1988). http://dx.doi.org/10.1002/pen.760280308

6. Iedema, P. D.; Willems, C.; Vliet, G.; Bunge, W.; Mutsers, S. M. P. \& Hoefsloot, H. C. J. - Chem. Eng. Sci., 56, p.3659 (2001). http://dx.doi. org/10.1016/S0009-2509(01)00054-9

7. Triacca, V. J.; Gloor, P. E.; Zhu, S.; Hrymak, A. N. \& Hamielec, A. E. - Polym. Eng. Sci., 33, p.445 (1993). http://dx.doi.org/10.1002/ pen.760330802

8. Azizi, H.; Ghasemi, I. \& Karrabi, M. - Polym. Test., 27, p.548 (2008). http://dx.doi.org/10.1016/j.polymertesting.2008.02.004

9. Machado, A. V.; Maia, J. M.; Canevarolo, S. V. \& Covas, J. A. - J. Appl. Polym. Sci., 91, p.2711 (2004). http://dx.doi.org/10.1002/app.13476 
10. Berzin, F.; Vergnes, B.; Canevarolo, S. V.; Machado, A. V. \& Covas, J. A. - J. Appl. Polym. Sci., 99, p.2082 (2006). http://dx.doi.org/10.1002/ app.22729

11. Berzin, F.; Vergnes, B. \& Delamare, L. - J. Appl. Polym. Sci., 80, p.1243 (2001). http://dx.doi.org/10.1002/app.1210

12. Suwanda, D.; Lew, R. \& Balke, S. T. - J. Appl. Polym. Sci., 35, p.1019 (1988). http://dx.doi.org/10.1002/app.1988.070350416

13. Ryu, S. H.; Gogos, C. G. \& Xanthos, M. - Adv. Polym. Tech., 11, p.121 (1991). http://dx.doi.org/10.1002/adv.1991.060110205

14. Norton, D. R. \& Keller, A. - Polymer, 26, p.704 (1985). http://dx.doi. org/10.1016/0032-3861(85)90108-9

15. Clark, E. S. \& Spruiell, J. E. - Polym. Eng. Sci., 16, p.176 (1976). http://dx.doi.org/10.1002/pen.760160310

16. Lu, F. M. \& Spruiell, J. E. - J. Appl. Polym. Sci., 34, p.1521 (1987). http://dx.doi.org/10.1002/app.1987.070340415

17. Misra, S.; Lu, F. M.; Spruiell, J. E. \& Richeson, G. C. - J. Appl. Polym. Sci., 56, p.1761 (1995). http://dx.doi.org/10.1002/app.1995.070561307

18. Andreassen, E.; Myhre, O. J.; Hinrichsen, E. L. \& Grøstad, K. - J. Appl. Polym. Sci., 52, p.1505 (1994). http://dx.doi.org/10.1002/ app.1994.070521015

19. Samuels, R.J. - Polym. Eng. Sci., 16, p.327 (1976). http://dx.doi. org/10.1002/pen.760160510

20. Wang, I. -C.; Dobb, M. G. \& Tomka, J. G. - J. Text. Inst., 87, p.1 (1996). http://dx.doi.org/10.1080/00405009608659051

21. Kamezawa, M.; Yamada, K. \& Takayanagi, M. - J. Appl. Polym. Sci., 24, p.1227 (1979). http://dx.doi.org/10.1002/app.1979.070240508

22. Kalantari, B.; Rahbar, R. S.; Mojtahedi, M. R. M.; Shoushtari, S. A. M. \& Khosroshahi, A. - J. Appl. Polym. Sci., 105, p.2287 (2007). http:// dx.doi.org/10.1002/app.26255

23. Pluta, M. - J. Microsc., 6, p.309 (1972). http://dx.doi. org/10.1111/j.1365-2818.1972.tb01061.x
24. Hemsley, D. A. - "Applied Polymer Light Microscopy", Elsevier Applied Science Publisher Ltd, London (1989). PMCid:318348. http:// dx.doi.org/10.1007/978-94-011-7474-9

25. Diacik, I.; Diacik, I. \& Jabmrich, M. - Acta Polym., 41, p.500 (1990). http://dx.doi.org/10.1002/actp.1990.010410908

26. Brandrup, J. \& Immergut, E. H. - "Polymer Handbook", 2nd ed., Wiley, New York (1975). PMid: 1145800.

27. Amash, A. \& Zugenmaier, P. - Polymer, 41, p.1589 (2000). http:// dx.doi.org/10.1016/S0032-3861(99)00273-6

28. Vasanthan, N. \& Salem, D. R. - J. Polym. Sci. Part B: Polym. Phys., 39, p.536 (2001). http://dx.doi.org/10.1002/10990488(20010301)39:5<536::AID-POLB1027>3.0.CO;2-8

29. Samuels, R. J. - "Structured Polymer Properties", Wiley, New York (1974).

30. Peterlin, A. - Polym. Eng. Sci., 17, p.183 (1977). http://dx.doi. org/10.1002/pen.760170307

31. Takayanagi, M.; Imada. K. \& Kajiyama, T. - J. Polym. Sci. Part C: Polym. Symp., 15, p.263 (1967). http://dx.doi.org/10.1002/ polc. 5070150118

32. Tadokoro, H. - Polymer, 25, p.147 (1984). http://dx.doi. org/10.1016/0032-3861(84)90321-5

33. Mirabella Junior, F. M. - J. Polym. Sci. Part B: Polym. Phys., 25, p.591 (1987). http://dx.doi.org/10.1002/polb.1987.090250310

34. Penning, J. P. - "Structure-properties relationships in polymeric fibers", PhD Dissertation, University of Groningen, Netherlands (1994).

35. He, T. - Polymer, 27, p.253 (1986). http://dx.doi.org/10.1016/00323861(86)90335-6

36. Peterlin, A. - J. Mat. Sci., 6, p.490 (1971). http://dx.doi.org/10.1007/ BF00550305

37. Williams, J. L. \& Peterlin, A. - J. Polym. Sci. A-2: Polym. Phys., 9, p.1483 (1971). http://dx.doi.org/10.1002/pol.1971.160090808

Enviado: 08/10/11 Aceito: 09/02/12 